\title{
TORSIONAL SHEAR DEVICE FOR TESTING THE DYNAMIC PROPERTIES OF RECYCLED MATERIAL
}

\author{
KATARZYNA GABRYŚ, WOJCIECH SAS \\ Laboratory - Water Centre, Warsaw University of Life Sciences - SGGW, \\ ul. Ciszewskiego 6,02-776 Warsaw, e-mail: katarzyna_gabrys@sggw.pl,wojciech_sas@sggw.pl \\ EMIL SOBÓL, ANDRZEJ GŁUCHOWSKI \\ Department of Geotechnical Engineering, Warsaw University of Life Sciences - SGGW, \\ ul. Nowoursynowska 159,02-776 Warsaw, e-mail: emil_sobol@sggw.pl, andrzej_gluchowski@sggw.pl
}

\begin{abstract}
From the viewpoint of environmental preservation and effective utilization of resources, it is beneficial and necessary to reuse wastes, for example, concrete, as the recycled aggregates for new materials. In this work, the dynamic behavior of such aggregates under low frequency torsional loading is studied. Results show that the properties of such artificial soils match with those reported in the literature for specific natural soils.
\end{abstract}

Key words: torsional shear test, shear modulus, material damping, recycled material

\section{INTRODUCTION}

Every year, more and more Construction and Demolition (C\&D) building waste is produced in the world. Their disposal has become a severe social and environmental issue in several countries (Ferguson [5]), thus highlighting the importance of their recycling and reuse. In many European countries, the recycling of demolition waste dates back to the end of World War II, being widely investigated for the past few decades (Hansen [8]).

In order to encourage sustainability, many governments throughout the world currently promote policies aimed at reducing the use of primary resources at the cost of increased application of reuse and recycling (Collins [2]). In this context, C\&D recycling aggregates may be used in different construction materials, reducing construction cost and environmental impact. For example, studies report the feasibility of mix granulate by using crushed concrete and stones as cement stabilizers, instead of the usual coarse natural or crushed aggregates (Xuan [18]). The suitability of recycled concrete aggregates for application in normal grade concretes meets industrial requirements for various applications, (e.g., foundations, paving, reinforced and pre-stressed concrete, see, e.g., Dhir et al. [3]). Data on the dynamic properties of such materials, such as shear modulus and damping, however, are remarkably limited. The present work tackles this problem by studying significant geotechnical parameters of recycled concrete aggregates as well as their possible usage as an alternative material in various construction activities.

\section{MATERIAL DESCRIPTION}

The experiments presented in this paper were performed on reclaimed concrete aggregates. They were collected from industrial building demolition sites in Warsaw, Poland. These aggregates were composed by $99 \%$ broken cement concrete from walls and floors (Fig. 1) and by $1 \%$ of glass and brick $\Sigma(\mathrm{Rb}, \mathrm{Rg}, \mathrm{X}) \leq$ $1 \% \mathrm{~m} / \mathrm{m}$, in accordance with EN 933-11:2009.

In laboratory, the recycled concrete was run through a set of sieves to segregate different particle sizes. The resulting particles were re-mixed in the proportion necessary to attain the grain-size distribution curve shown in Fig. 2. Such a ratio of particles was chosen to meet Polish technical standards (WT-4). 
According to the Polish Committee for Standardization (2013) of soil, the test material obtained was classified as sandy gravel (saGr).

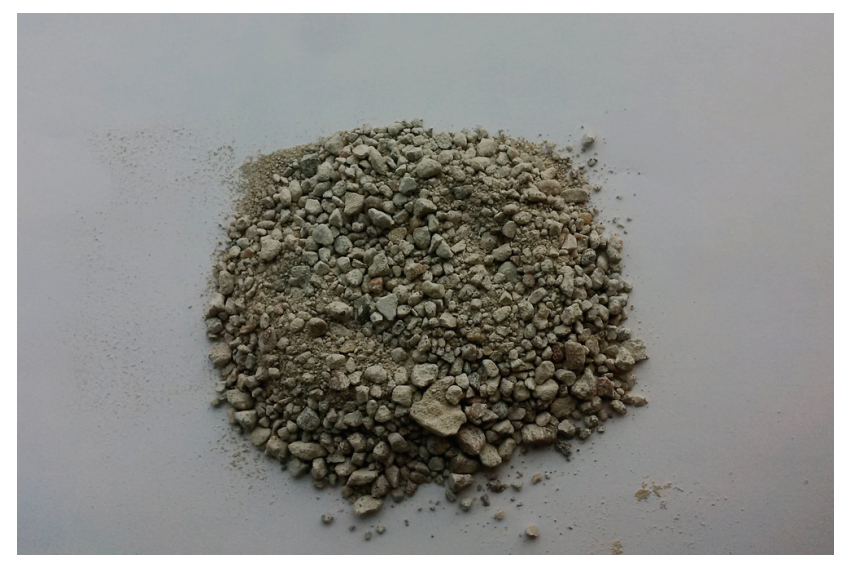

Fig. 1. Crushed concrete sample as used in testing

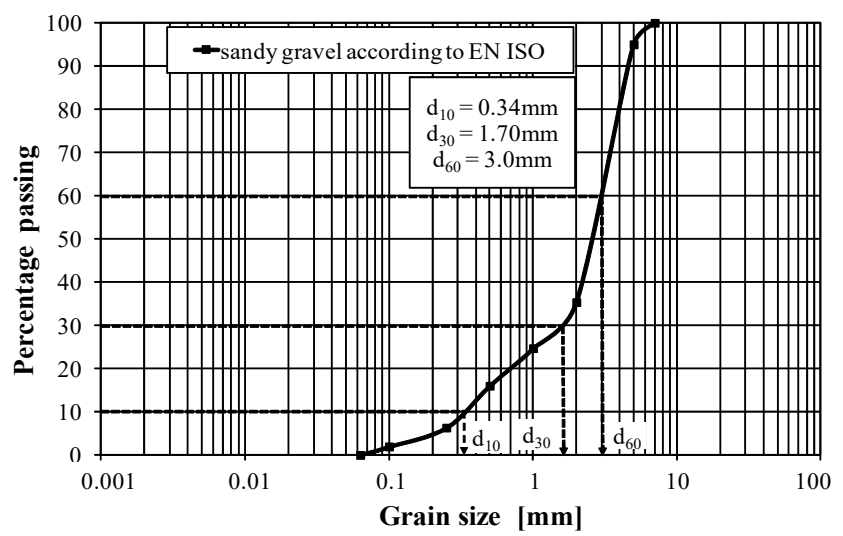

Fig. 2. Grain-size distribution of the material tested, where $d_{10}$ is the grain diameter of $10 \%$ passing, $d_{30}$ is the grain diameter of $30 \%$ passing and $d_{60}$ is the grain diameter of $60 \%$ passing

After the desired particle distribution was achieved, the material was mixed with water $(12 \%$ of its net weigh), allowing an optimum moisture content to be achieved. In order to determine experimentally the optimum moisture content, the Proctor compaction test was selected. The energy of the compaction process was equal to that of the standard Proctor test, i.e., $0.59 \mathrm{~J} \cdot \mathrm{cm}^{-3}$. The hydrated aggregates were afterwards poured in cylindrical moulds with $70 \mathrm{~mm}$ radius and
$140 \mathrm{~mm}$ height and compacted with a metal compactor. This resulted in cylindrical samples with similar dimensions. The density measurements were performed after the dynamic tests.

The major physical characteristics of the resulting specimens are given in Table 1. The specimen's coefficient of uniformity $\left(C_{u}\right)$ and coefficient of curvature $\left(C_{c}\right)$, corresponding to $C_{u}=\frac{d_{60}}{d_{10}}$ and $C_{c}=\frac{d_{30}^{2}}{d_{10} \cdot d_{60}}$, amounted to $C_{u}=8.82$ and $C_{c}=2.83$, respectively. $C_{u}$ is a crude shape parameter, which allows soil gradation to be classified, whereas $C_{c}$ is an another coefficient to characterize gradation indicating, e.g., the potential of interlocking. The values of these coefficients suggest a well-graded material, susceptible to compaction process and suitable for the construction of embankments.

\section{EXPERIMENTAL SETUP}

The equipment used by the authors was an upgraded version of the resonant column apparatus (RCA) used by Gabryś et al. [6]. The instrumentation used here differed from that of Gabryś et al. [6] by the addition of a new GDS RCA Control Box module, shown in Fig. 3 (GDS Control Box version 2; for details refer to GDS Resonant Column, 2011).

This new model of the GDS RCA Control Box (version 2) allows for more reliable measurements of the peak shear strain in torsional shear tests with a precision of $1 \cdot 10^{-6}$, compared to the shear strain range of $1 \cdot 10^{-5} \div 1 \cdot 10^{-2}$ obtained in the standard GDS RCA Control Box (version 1) from Gabryś et al. [6]. In addition to the new Control Box, the improved experimental accuracy can be attributed to the inclusion to the experimental setup of a higher precision proximitor with a hardware offset potentiometer, two selectable proximitor gain channels, and two input channels for logging axial displacement and pore water pressure.

Table 1. Physical characteristics of the soil tested

\begin{tabular}{|c|c|c|c|c|c|c|c|c|}
\hline \multirow{3}{*}{ Material } & $W$ & $\rho_{\mathrm{s}}$ & $\rho$ & $\rho_{\mathrm{d}}$ & $e$ & $\theta$ & $R_{\mathrm{S}}$ & $D_{\mathrm{r}}$ \\
\cline { 2 - 8 } & {$[\%]$} & {$\left[\mathrm{g} / \mathrm{cm}^{3}\right]$} & {$\left[\mathrm{g} / \mathrm{cm}^{3}\right]$} & {$\left[\mathrm{g} / \mathrm{cm}^{3}\right]$} & {$[-]$} & {$[\%]$} & {$[-]$} & {$[-]$} \\
\hline $\mathrm{saGr}$ & 11.16 & 2.60 & 1.80 & 1.62 & 0.60 & 28.50 & 0.48 & 0.95 \\
\hline
\end{tabular}

Note: $W=$ water content; $\rho_{s}=$ soil particle density; $\rho=$ bulk density of soil mass; $\rho_{d}=$ bulk density of soil skeleton; $e=$ void ratio; $\theta=$ volumetric water content; $R_{S}=$ saturation ratio; $D_{r}=$ relative density. 


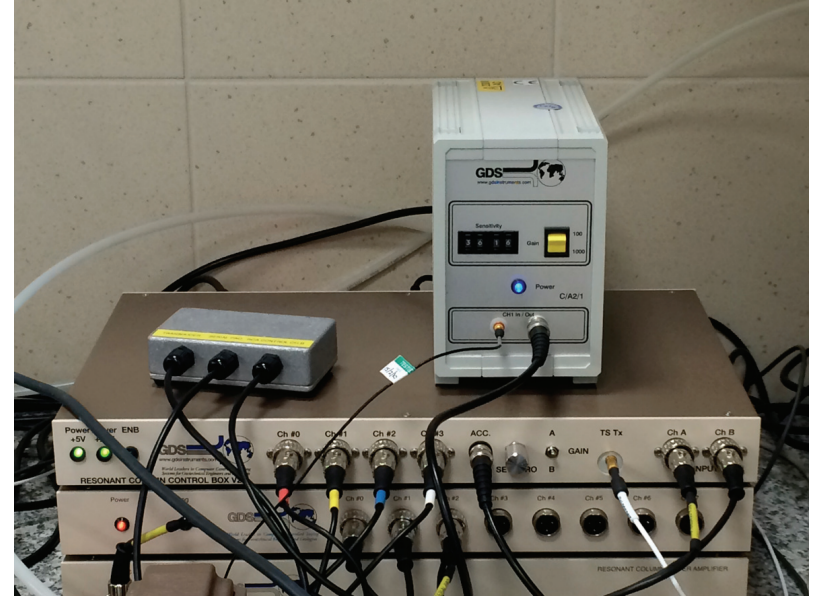

Fig. 3. GDS RCA Control Box v2

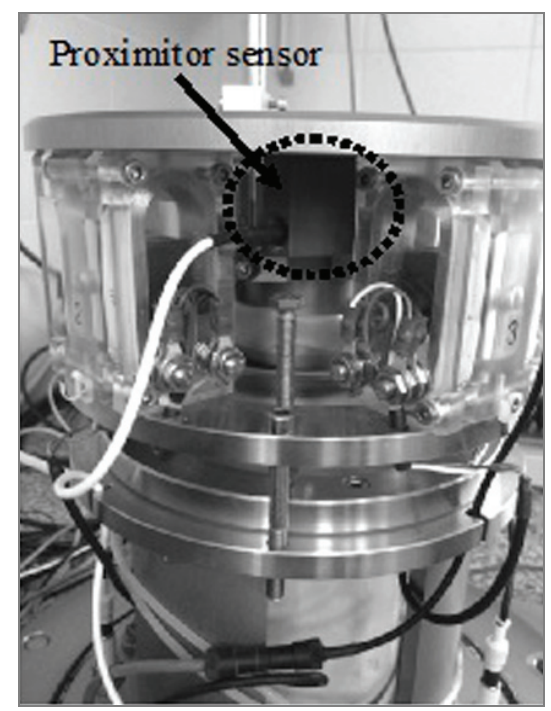

The new high-precision proximitor encompassed two components: a sensor and target plates. The target plates are attached to the RCA rotor arm as shown in Fig. 4 and move when the sample is excited. The sensor is mounted on the (fixed) plate of the RCA drive system and monitors the lateral displacement of the target metal plate, as shown in Fig. 4 (GDS Resonant Column, 2011).

In addition to the hardware upgrades, an improved version of the GDS RCA software was used. Such modified version contained updated calibration settings for the proximitor and transducer input channels. It also allowed for digital noise filtering of the torsional shear data, further easing the data treatment.

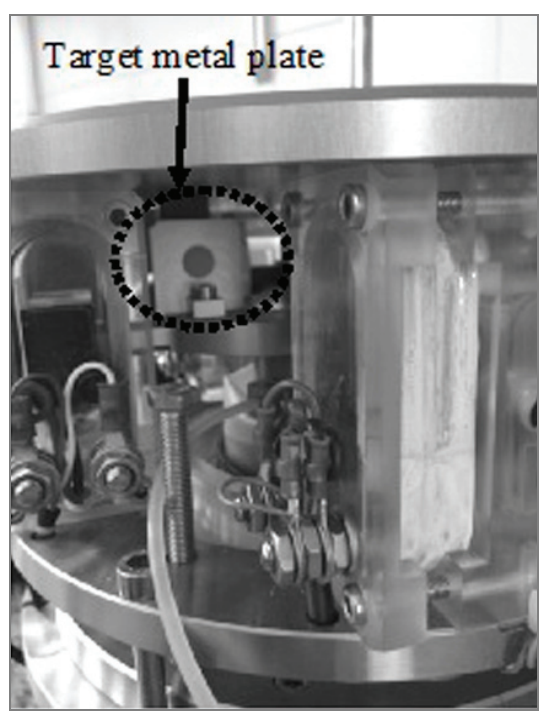

Fig. 4. Location of proximitor on the drive system

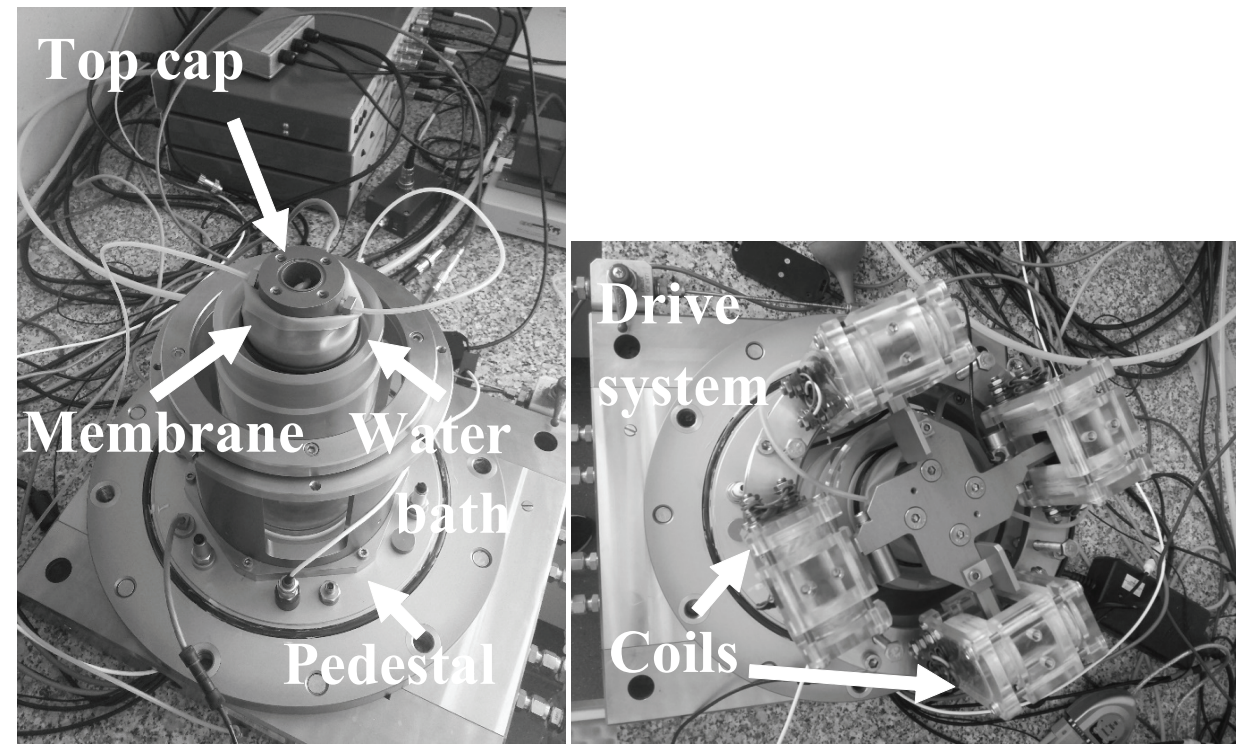

Fig. 5. Arrangement of the RCA device 
For the measurements, the following hardware arrangement around a specimen (Fig. 5) was followed:

- The sample was placed on the pedestal at the base of the equipment;

- A top cap was installed on the sample;

- The sides of the sample were enclosed with an impermeable membrane;

- An aerated water bath was introduced around the sample;

- The RCA top cap's electronic systems were connected to their respective controllers;

- The pressure chamber was sealed.

\section{EXPERIMENTAL METHODS}

The recycled aggregates presented here were characterized using torsional shear tests. For this purpose, resonant column (RC) and torsional shear (TS) devices were used. These complementary devices can apply torsional and triaxial loads in soil samples. The main difference between the two devices is in the range of frequency and the amplitude of excitations. TS tests are static, or quasi-static cyclic tests, during which an axially confined cylindrical sample is sheared through rotating one of its ends. An advantage of this method is that the bedding has a minimum effect on the test final results (Benz [1]). In RC tests, on the other hand, an axially confined cylindrical specimen is vibrated by means of torsional or longitudinal excitation of one of its ends. This allows the sample resonant frequency $(f)$ to be determined, which can be related to the device's stiffness using a theoretical elastic model. This procedure provides satisfactory results in the small-strain range (Sas et al. [13]).

The application of cyclic torsional shear tests to measure the shear modulus $(G)$ and the material damping $(D)$ of a soil sample has been experimentally demonstrated by Isenhower [10] and $\mathrm{Ni}$ [11]. The technique is based on the stress-strain relationship hysteresis loop, which is obtained by cycling a known torque at the top of the specimen and measuring the resulting displacement by means of a proximitor on the same sample end (see Fig. 6).

The shear modulus $(G)$ is obtained by evaluating the slope of the line connecting both ends of the stress-strain hysteresis loop (see Fig. 6). Formally, this value is defined as the secant shear modulus and is given by

$$
G=\frac{\tau}{\gamma}
$$

where $\tau$ is the shear stress and $\gamma$ the distortion angle equal to double the shear strain.

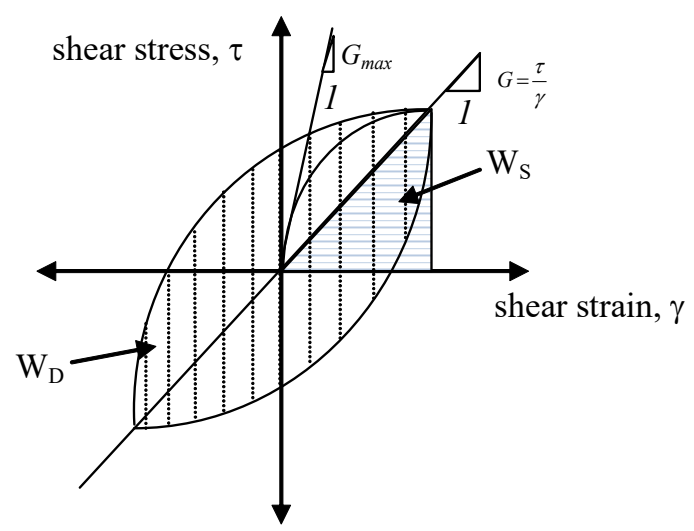

Fig. 6. Concept of the shear modulus and the material damping ratio in the torsional shear test ( $W_{D}$ - the area of the stippled hysteresis loop, $W_{S}-$ the area of the lined triangle) (Zhang et al. [17])

\section{Shear modulus}

The shear stress $\tau$ is determined from the applied shearing torque $(T)$ based on the theory of elasticity for a cylindrical bar with radius $\left(r_{\max }\right)$. In the elastic regime, $\tau$ varies linearly with the bar radius. In this approximation, the sample average shear stress $\left(\tau_{\text {avg }}\right)$ is given by

$$
\tau_{\text {avg }}=\frac{r_{\mathrm{eq}} T}{J},
$$

where $r_{\mathrm{eq}}$ is the equivalent radius

$$
r_{\text {eq }}=\frac{2}{3} r_{\max }
$$

and $J$ is the polar moment of inertia of the crosssection of a cylinder

$$
J=\frac{\pi r^{4}}{2} .
$$

In the RCA used in this work, the applied torque is calculated from the voltage $\left(V_{T}\right)$ used to drive the coils responsible for the sample loading (see Fig. 5). The applied torque $(T)$ relates linearly to $V_{T}$ according to $T=K_{T} \cdot V_{T}$, with $K_{T}$ a calibration factor. Hence, equation (2) can be rewritten as follows

$$
\tau_{\text {avg }}=\frac{r_{\mathrm{eq}} K_{T} V_{T}}{J} .
$$

The average shear strain, according to Hardin and Drnevich [9], is given by

$$
\gamma_{\text {avg }}=\frac{2}{3}\left(\frac{r_{\max } \theta_{\max }}{1}\right),
$$


where $\theta_{\max }$ is the rotation angle caused by the torque $T$ (see, e.g., Gabryś [7]). In the RCA, $\theta_{\max }$ can be measured with a rotary variable differential transformer (RVDT). Such device outputs a voltage $\left(V_{r}\right)$, which relates to $\theta_{\max }$ by calibration factor $K_{r}$, according to $\theta_{\max }=K_{r} \cdot V_{r}$. Using equation (3), equation (6) can be rewritten as

$$
\gamma_{\mathrm{eq}}=\frac{r_{\mathrm{eq}} K_{T} V_{T}}{1}
$$

It is stressed that equations (5) and (7) only apply if the soil is in the elastic regime, which typically occur in the low range of strains $(0.001 \%$ and less $)$. At strains above $0.001 \%$, equations (5) and (7) provide lower limits of $\gamma_{\text {avg }}$ and $\tau_{\text {avg }}$ (Zavoral [16]).

\section{Damping ratio}

The material damping ratio $(D)$ in the torsional shear test is obtained by comparing the work $\left(W_{D}\right)$ done by the system with its elastic potential energy $\left(W_{S}\right)$. These values correspond, respectively, to the area inside the stress-strain hysteresis loop for a cycle of loading and the product of the maximum shear stress and maximum shear strain (see Fig 6). For a system with a single degree of freedom, $W_{D}$ is given by

$$
W_{D}=2 \pi D k x^{2}
$$

and $W_{S}$ by

$$
W_{S}=\frac{k x^{2}}{2}
$$

with $D$ the damping ratio, $k$ a spring constant, and $x$ the sample displacement. Combining equations (8) and (9) yields

$$
D=\frac{W_{D}}{4 \pi W_{S}} .
$$

Equation (10) provides for the calculation of the damping ratio for any cycle of loading for a system at resonance. This expression describes systems outside resonance as well, due to the weak interplay between oscillating frequency and damping, as reported by $\mathrm{Ni}$ [11].

\section{EXPERIMENTAL PROGRAM}

Experimental program included subjecting the top of the specimen to a low-frequency torsional loadings

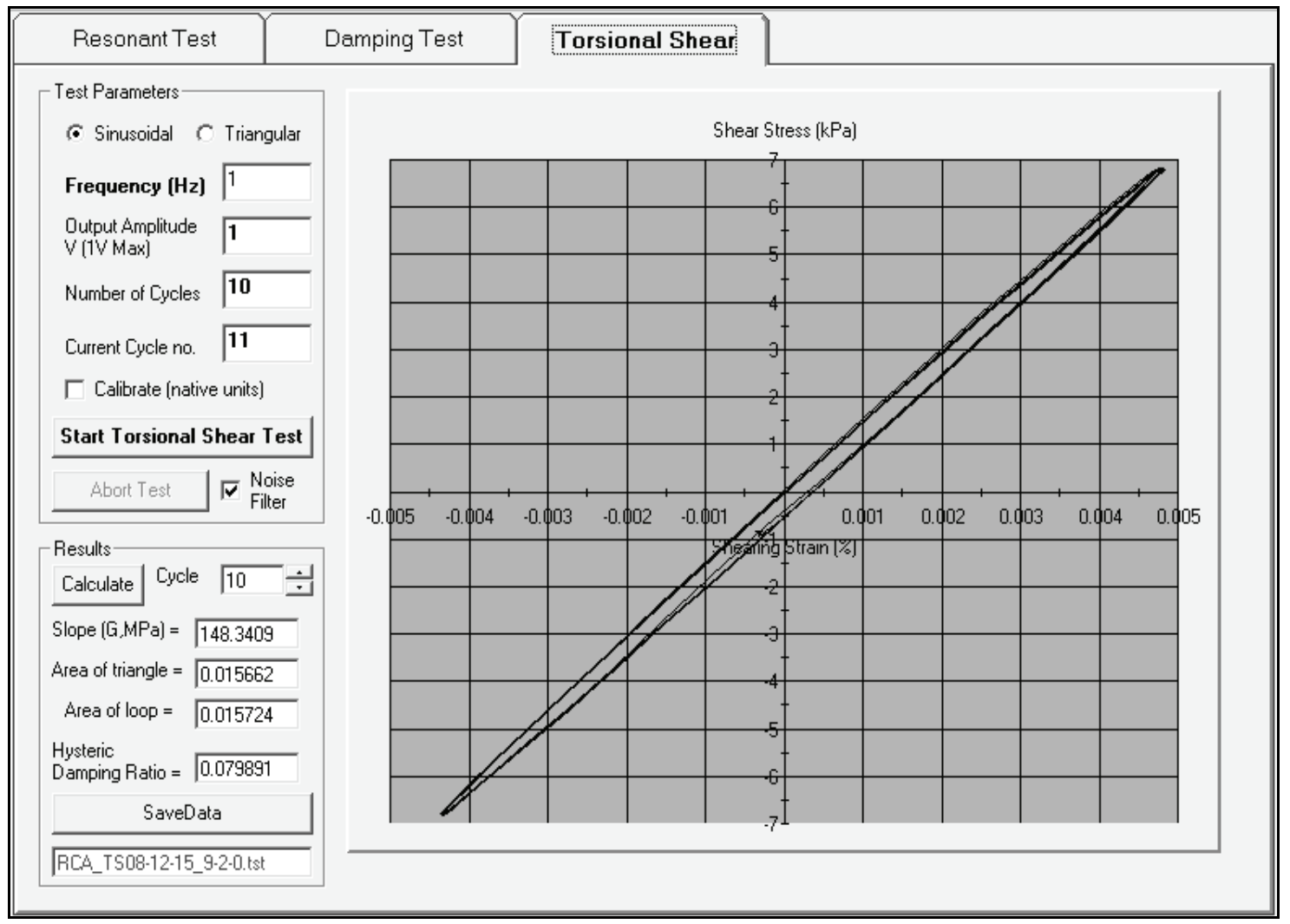

Fig. 7. An example result of hysteresis loop measured in TS test.

The dashed line connects both ends of the loop and its slope represents the sample's shear modulus 
(torsional shear test), followed by a high-frequency loading (resonant column test). Such measurements were repeated under different applied confining pressures. In the current work, mainly TS results will be discussed.

Torsional shear tests were conducted by applying torsional loadings with frequencies $0.1 \mathrm{~Hz}, 1 \mathrm{~Hz}$ and $10 \mathrm{~Hz}$ to the test specimen. Such measurements were performed with the examined material under increasingly higher effective stresses $\left(p^{\prime}\right)$. Experiments were performed for $p^{\prime}=45,90,135,180$ and $225 \mathrm{kPa}$ (experiments at lower pressures were performed first). Each test was repeated at several loading amplitudes, varying between $0.005 \mathrm{~V}$ and $1.0 \mathrm{~V}$.

After the last TS tests at $p^{\prime}=225 \mathrm{kPa}$ had been carried out, the sample was unloaded to $45 \mathrm{kPa}$ and a second loading process was conducted up to $p^{\prime}=$ $315 \mathrm{kPa}$. The aim of this sequence loading was to study the variation in the shear modulus and the damping ratio values as a function of the mean effective stress. For each set of parameters (applied frequency, confining pressure, loading amplitude), 10 loading cycles were measured. All the calculations shown here refer to the last (10th) cycle. A typical TS test result is shown in Fig. 7. The extraction of relevant parameters from the curves were carried out as described in Section 4.

\section{RESULTS AND DISCUSSION}

Results of the cyclic TS tests are presented in Figs. 8, 9 and 10. The samples' shear modulus $(G)$ and damping ratio $(D)$ showed a distinct decrease and increase, respectively, with increasing shear strain $(\gamma)$, respectively. This is shown in Fig. 8. Values of $G$ indicated a weak dependence on the excitation fre-
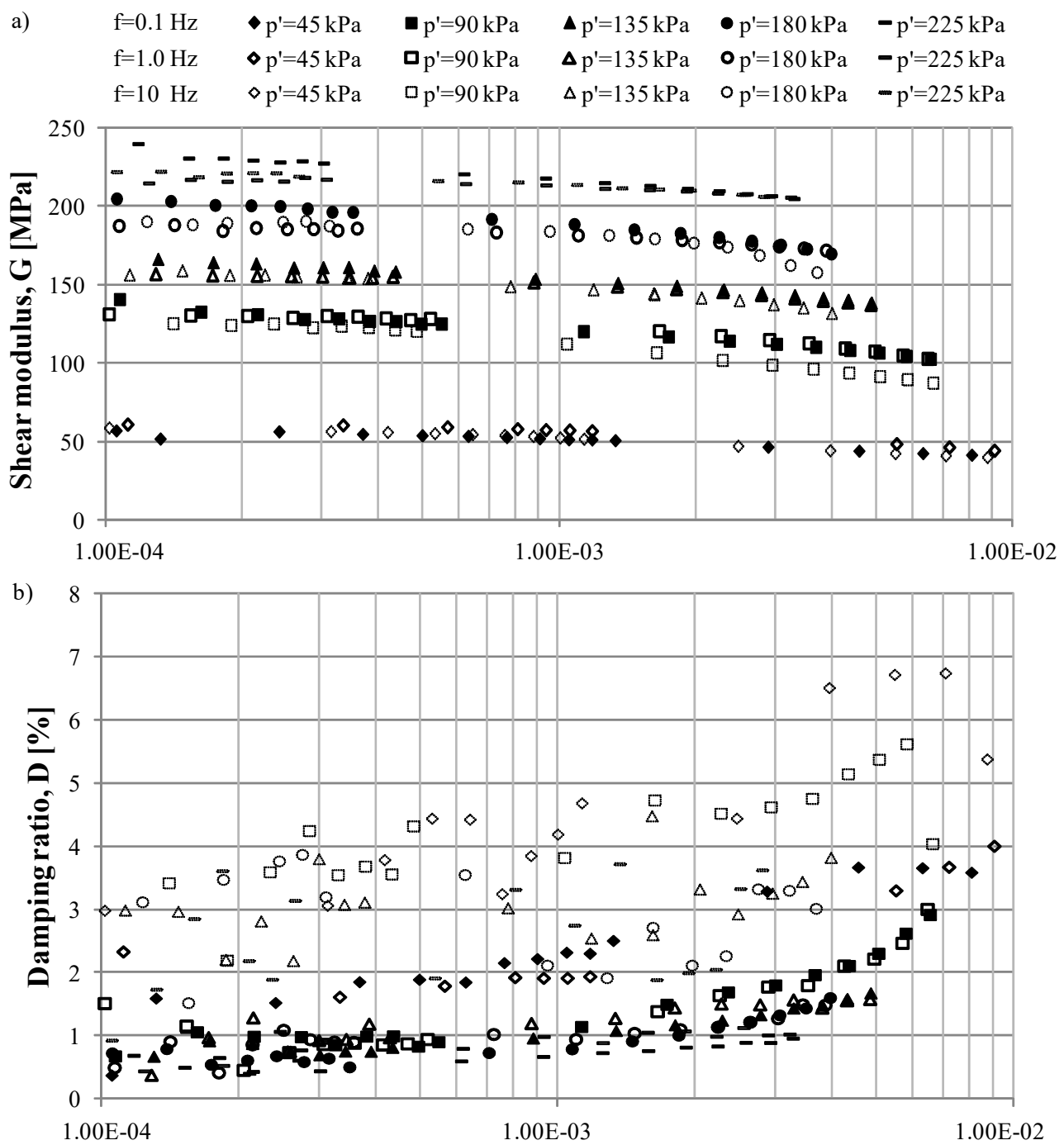

Shearing strain amplitude, $\gamma[\%]$

Fig. 8. Shear modulus (a) and damping ratio (b) as a function of shearing strain amplitude for test sample 

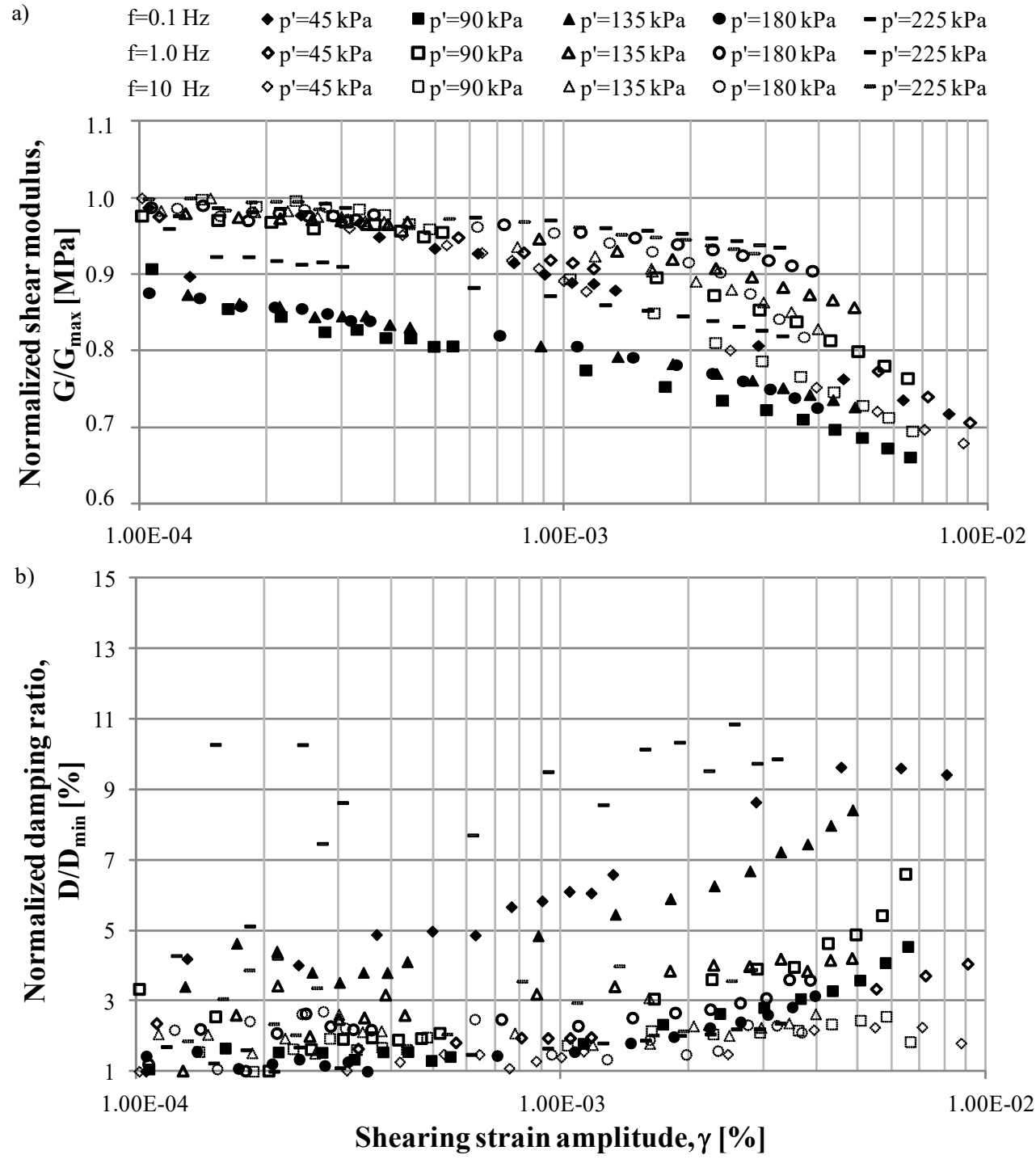

Fig. 9. Normalized shear modulus (a) and normalized damping ratio (b) as a function of shearing strain amplitude for test sample

quency, but a strong sensitivity to $p^{\prime}$ and $\gamma$. This is denoted by the low dispersion of $G$ values in the $y$-direction for different frequencies. The average difference between $G$ values measured at the highest and lowest available $\gamma\left(\gamma_{\max }\right.$ and $\gamma_{\min }$, respectively) over $p^{\prime}$, given by

$$
\Delta G(f)=\frac{1}{5} \sum_{p^{\prime}}\left[G\left(p^{\prime}, f, \gamma_{\max }\right)-G\left(p^{\prime}, f, \lambda_{\min }\right)\right]
$$

amounted to $\Delta G(0.1 \mathrm{~Hz})=-46 \mathrm{MPa}, \Delta G(1 \mathrm{~Hz})=$ $-22 \mathrm{MPa}$ and $\Delta G(10 \mathrm{~Hz})=-27 \mathrm{MPa}$. As opposed to the $G$-data, damping values presented scattered results, particularly for $f=10 \mathrm{~Hz}$ (see Fig. 8b). Values of $\Delta D$ (calculated akin to those of $\Delta G$ ) amounted to $\Delta D(0.1 \mathrm{~Hz})=2.2 \%, \Delta D(1 \mathrm{~Hz})=2.7 \%$ and $\Delta D(10 \mathrm{~Hz})=3.4 \%$, respectively.
The normalized shear modulus $\left(G / G_{\max }\right)$ and material damping $\left(D / D_{\min }\right)$ at different $f$ and $p^{\prime}$ are shown as a function of $\gamma$ in Fig. 9. Despite the large point dispersion observed in Fig. 9b, results clearly showed a strong influence of $p^{\prime}$ on the normalized values of the dynamic properties of the recycled material. $G / G_{\max }$ and $D / D_{\min }$ decreased and increased with $p^{\prime}$, respectively. The large data scattering observed for $D / D_{\min }$ can be attributed to the damping results from the torsional shear tests in Fig. $10 \mathrm{~b}$.

The values of the low-amplitude shear modulus $\left(G_{\max }\right)$ and damping ratio $\left(D_{\min }\right)$ at different $p^{\prime}$ are plotted against the excitation frequency $(f)$ in Fig. 10. Results of $G_{\max }$ (Fig. 10a) presented values ranging between $57 \mathrm{MPa}\left(p^{\prime}=45 \mathrm{kPa}\right.$ and $\left.f=0.1 \mathrm{~Hz}\right)$ and $250 \mathrm{MPa}\left(p^{\prime}=225 \mathrm{kPa}\right.$ and $\left.f=0.1 \mathrm{~Hz}\right)$, with the largest value of $G_{\max }$ obtained for the lowest excitation 

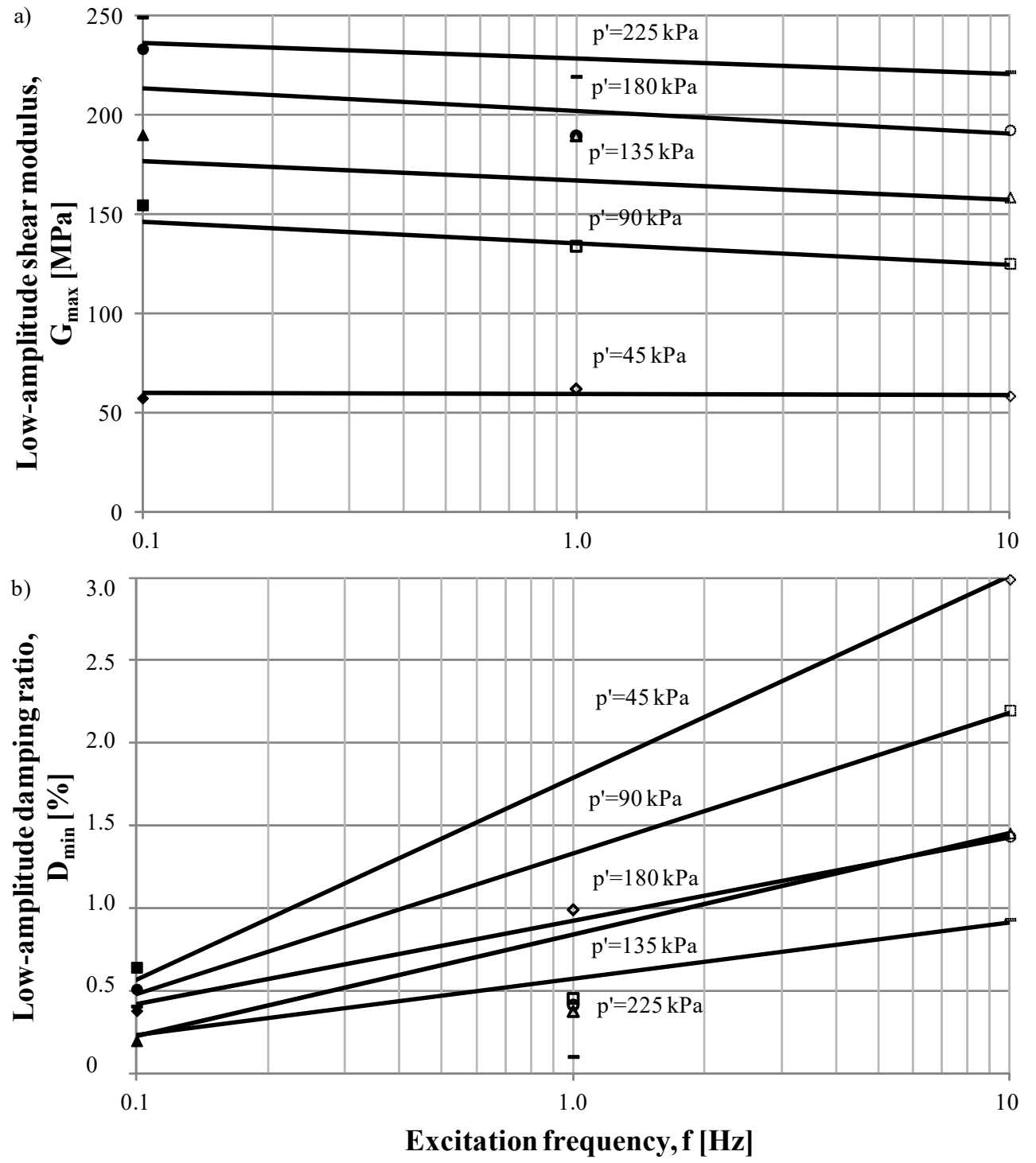

Fig. 10. Low-amplitude shear modulus (a) and low-amplitude damping ratio (b) as a function of excitation frequency for test sample

frequency $(f=0.1 \mathrm{~Hz})$. With increasing $f, G_{\max }$ values decreased between $7 \%$ (for $p^{\prime}=45 \mathrm{kPa}$ ) and $19 \%$ (for $\left.p^{\prime}=180 \mathrm{kPa}\right)$. The point dispersion suggests that such decrease is linear in $f$ in semi-log scale, however, in fact it means that the modulus exhibits a nonlinear dependence on the excitation frequency (see Fig. 10a).

The values of the low-amplitude damping ratio $\left(D_{\min }\right)$ were in the interval between $0.1 \%\left(p^{\prime}=225 \mathrm{kPa}\right.$ and $f=1.0 \mathrm{~Hz})$ and $3 \%\left(p^{\prime}=45 \mathrm{kPa}\right.$ and $\left.f=10 \mathrm{~Hz}\right)$ (Fig. 10b), with the lowest $D_{\min }$ obtained for the mean excitation frequency $f=1.0 \mathrm{~Hz}$. The dependence of $D_{\min }$ with $f$ was positive, presenting an increase ranging from $71 \%$ (at the mean effective stress $p^{\prime}=$ $180 \mathrm{kPa}$ ) to $87 \%$ (at $p^{\prime}=45 \mathrm{kPa}$ ). Similarly to $G_{\max }$ values, the low dispersion of $D_{\min }$ suggest that its increase is linear in $f$ in semi-log scale (see Fig. 10b).

\section{Comparison with previously published results for natural soils}

The dynamic properties of recycled material were next compared with the results of Sas et al. [14] in Figs. 11 and 12. Sas et al. in their research conducted also torsional shear tests on the natural soil samples (sandy clay - clSa according to the Polish Committee for Standardization [12]), obtained from a village called Kociszew (South Poland), collected from the depth of about $6.0 \mathrm{~m}$. For simplicity, only the results for the excitation frequency $f=1.0 \mathrm{~Hz}$ were presented here. As shown in Fig. 11, the curves illustrating the dependence of $G_{\max }$ on $p^{\prime}$ are similar for both materials and a significant effect of $p^{\prime}$ on the low-amplitude shear modulus was observed. On the basis of the pro- 


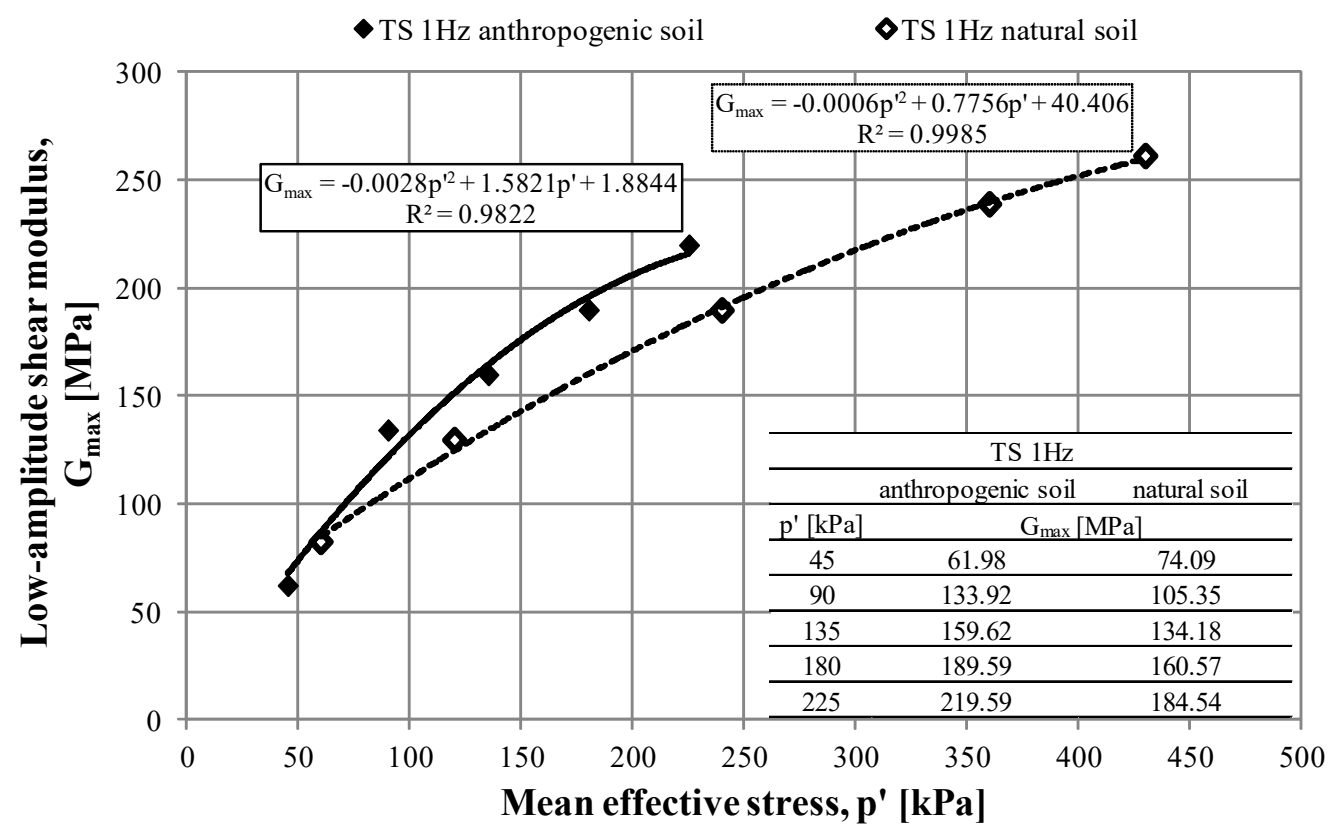

Fig. 11. Comparison of low-amplitude shear modulus of anthropogenic soil tested with natural soil from Sas et al. [14]
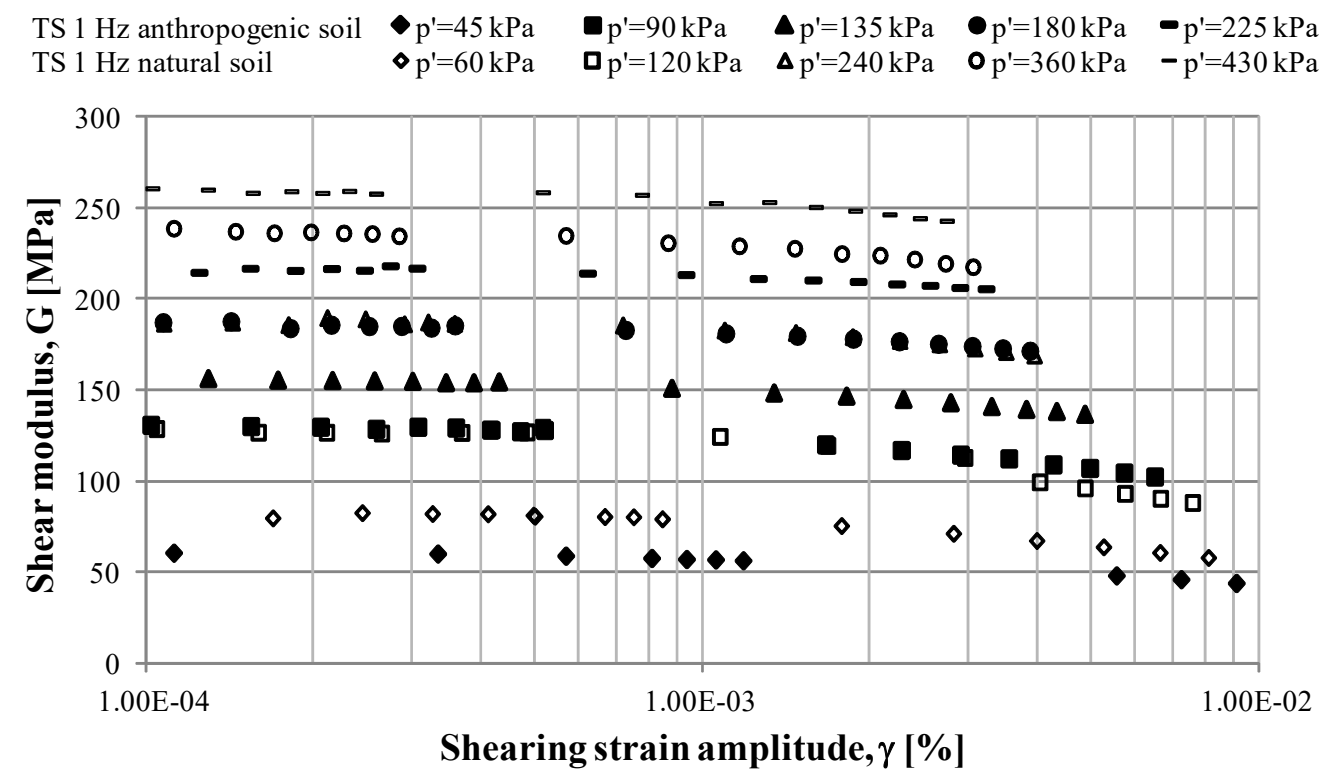

Fig. 12. Comparison of shear modulus of anthropogenic soil tested with natural soil from Sas et al. [14]

posed regression functions (see Fig. 11), the missing $G_{\max }$ values of specific natural soil were additionally calculated for the same $p^{\prime}$ as used in TS tests on the recycled aggregates. The differences between the $G_{\max }$ results were an average of $17 \%$ in favour of the artificial (anthropogenic) soils.

In Fig. 12, a combination of the shear modulus $(G)$ variation with the shear strain $(\gamma)$ for anthropogenic and natural soils is shown. The shear modulus kept at a highest value as long as the shearing strain is less than one certain value. It was noticed as well that the shear modulus $(G)$ of the anthropogenic ma- terial tested had the same tendency to change with the shear strain $(\gamma)$ as the natural soil has. With an increase in strain amplitude beyond a threshold level, the results of $G$ demonstrated an apparent nonlinearity in nature.

\section{CONCLUSIONS}

In this paper, the research methodology used in GDS RC/TS apparatus has been presented, with 
tests performed on the recycled concrete aggregates. The tests conducted in TS apparatus enabled a reliable determination of the sample's shear modulus $(G)$ and viscous damping ratio $(D)$ in the range from small to moderate strains. $G$ values measured this way displayed similar trends to other soils, as reported in the literature. In fact, this means that the low-amplitude shear modulus exhibits a nonlinear dependence on effective stress, and the shear modulus demonstrates nonlinear change with varying shear strain.

The results clearly showed that both, the shear modulus and the damping ratio, of the synthetic soil studied were strongly affected by the increasing shearing strain amplitude $(\gamma)$ and the mean effective stress $\left(p^{\prime}\right)$. The average difference between $G$ values measured at the highest $\left(\gamma_{\max }\right)$ and lowest $\left(\gamma_{\min }\right)$ shear strains was in the range of 22 to $46 \mathrm{MPa}$. Regarding $D$ values, the results of $\Delta D$ amounted from 2.2 to $3.4 \%$. Ratios $G / G_{\max }$ and $D / D_{\min }$ of the anthropogenic material tested decreased on average by about $220 \mathrm{kPa}$ and increased on average by about $5.2 \%$, respectively. It was also shown that $G_{\max }$ and $D_{\min }$ were influenced by the excitation frequency $(f)$, respectively decreasing and increasing with $f$. The greatest value of $G_{\max }$ $\left(G_{\max }=249.5 \mathrm{MPa}\right)$ was obtained for the lowest excitation frequency $(f=0.1 \mathrm{~Hz})$ when $p^{\prime}=225 \mathrm{kPa}$, whereas for the highest $f(f=10 \mathrm{~Hz})$ and $p^{\prime}=45 \mathrm{kPa}$ the lowest $G_{\max }$ value of $58.6 \mathrm{MPa}$ was reached. An average decline of about $15 \%$ in the values of $G_{\max }$ was recorded. Concerning the low-amplitude damping ratio $\left(D_{\min }\right)$, its lowest value $\left(D_{\min }=0.1 \%\right)$ was obtained for the mean excitation frequency, i.e., $1.0 \mathrm{~Hz}$, and $p^{\prime}=225 \mathrm{kPa}$ and its highest value $\left(D_{\min }=3 \%\right)$ for $f=10 \mathrm{~Hz}$ and $p^{\prime}=45 \mathrm{kPa}$. The experimental results also showed that an average increase in $D_{\min }$ values was equal to approx. $83 \%$.

The authors consider that more testing is necessary in order to define other possible factors probably affecting the shear modulus and the damping ratio of dynamically loaded recycled materials.

\section{ACKNOWLEDGMENT}

The discussion about the results obtained was carried out with the valuable support of Bruno Cury Camargo (LNCMI - Laboratoire National des Champs Magnetiques Intenses, Toulouse, France).

\section{REFERENCES}

[1] Benz T., Small-Strain Stiffness of Soils and its Numerical Consequences, Dissertation, Institut für Geotechnik, Universität Stuttgart, Germany, 2007.
[2] Collins R.J., Recycled aggregate in ready mix, Concrete, Engineering International, 1998, 49-54.

[3] DhiR R.K., Limbachiya M.C., Leelawat T., Suitability of recycled concrete aggregate for use in $B S 5328$ designated mixes, Proceedings of ICE: Structures \& Buildings, August. 1999, 134 (3), 257-274.

[4] European Committee for Standardization. (2009). Tests for geometrical properties of aggregates. Classification test the constituents of coarse recycled aggregate, EN 933-11:2009.

[5] Ferguson J., Managing and Minimizing Construction Waste: a Practical Guide[M], Thomas Telford Publications, London, UK, 1995.

[6] GABryś K., SAS W., SzymańSKi A., Kolumna rezonansowa jako urządzenie do badań dynamicznych gruntów spoistych (Resonant Column Apparatus as a device for dynamic testing of cohesive soils), Przegląd Naukowy Inżynieria i Kształtowanie Środowiska Scientific Review - Engineering and Environmental Sciences, 2013, 22(1), 59, 3-13, (in Polish).

[7] GABRYŚ K., Charakterystyki odksztatceniowe wybranych gruntów spoistych (Deformation characteristics of selected cohesive soils), Ph.D. Thesis. Department of Civil- and Environmental Engineering, Warsaw University of Life Sciences, Warsaw, Poland, 2014, (in Polish).

[8] HANSEN T.C., Recycling of Demolished Concrete and Masonry [R], Report of Technical Committee 37-DRC, RILEM, 1992.

[9] Hardin B.O., Drnevich V.P., Shear Modulus and Damping in Soils: Measurement and Parameter effect, Journal of Soil Mechanics and Foundations Division, ASCE, 1972, 98(6), 603-624.

[10] IsENHOWER W.M., Torsional Simple Shear/Resonant Column Properties of San Francisco Bay Mud, MSc Thesis, Civil Engineering Department, University of Texas at Austin, Austin, Texas, 1979.

[11] Ni S.H., Dynamic Properties of Sand under True Triaxial Stress States from Resonant Column/Torsional Shear Tests, Ph.D. Thesis, Civil Engineering Department, University of Texas at Austin, Austin, Texas, 1987.

[12] Polish Committee for Standardization (2013). Geotechnical investigation and testing - Identification and classification of soil-Part 2: Principles for a classification PN-EN 14688-2.

[13] SAS W., GABRYŚ K., SZYMAŃSKi A., Effect of Time on Dynamic Shear Modulus of Selected Cohesive Soil on One Section of Express Way No. S2 in Warsaw, Acta Geophysica, 2015, 63(2), 398-413, DOI: 10.2478/s11600-014-0256-z.

[14] Sas W., Soból E., Gabryś K., Markowska-Lech K., Study of the cohesive soil stiffness in a modified resonant column, [in:] Materiały Konferencji Naukowych XVII Warsztaty Górnicze II Sympozjum Geofizyczne, Applied Geophysics, 2016, Gdańsk, 1-3 June 2016 (1-15).

[15] WT-4. Unbound mixtures for national roads. Available online: http://www.gddkia.gov.pl/userfiles/articles/d/Dokumenty_ techniczne/WT4.pdf. (in Polish).

[16] Zavoral D., Dynamic properties of an undisturbed clay from resonant column tests, MSc Thesis, Civil engineering Department, University of British Columbia, Vancouver, Canada, 1990.

[17] Zhang J.F., Andrus R.D., JuAng C.H., Normalized Shear Modulus and Material Damping Ratio Relationships, Journal of Geotechnical and Geoenvironmental Engineering, ASCE, 2005, 131(4), 453-464, DOI: 10.1061/(ASCE)1090-0241.

[18] XuAn D.X., Literature Review of Research Project: Structural Properties of Cement Treated Materials [R], Report 7-09-217-1, Section Road and Railway Engineering, Delft University of Technology, the Netherlands, 2009. 